Cezary Kulesza

\title{
ПРОЕКТИРУЕМАЯ НОВЕЛЛИЗАЦИЯ ПРОЦЕДУРЫ ПОЛЬСКОГО УГОЛОВНОГО СУДОПРОИЗВОДСТВА С ПЕРСПЕКТИВЫ НЕКОТОРЫХ ПРИНЦИПОВ УГОЛОВНО-ПРОЦЕССУАЛЬНОГО ПРАВА
}

Учреждена в конце 2009 года кодификционная комиссия уголовного права, действующая при Министре юстиции, сочла своей главной задачей подготовку фундаментальной новеллизации положений уголовного судопроизводства. Приступая к работе, комиссия приняла предположение, что существующая до сих пор модель уголовного судопроизводства постепенно исчерпывает свои возможности. комиссия признала необходимым введение изменений, которые должны противодействовать чрезмерному затягиванию производства по делу, а также чрезмерной продолжительности применяемого в Польше временного ареста, на что обратил внимание Европейский суд по правам человека в Страсбурге, подчеркивая, что это польская проблема структурного характера. ${ }^{1}$

Для того, чтобы узнать мнение среды судебных практиков органов юстиции, комиссия организовала в 2010 году под покровительством Министерства юстиции три научно-практические конференции, посвященные: модели подготовительного и юрисдикционного производства, применению мер принуждения в уголовном процессе и модели инстанционного [иерархического] и внеинстанционного контроля. Основой этих конференций были доклады, подготовленные экспертами в этих областях уголовного процесса, которые, после их представления, стали предметом оживленной дискуссии. ${ }^{2}$

Итак, по отношению к модели подготовительного производства в заключениях экспертов ${ }^{3}$, подготовленных на конференцию 30 марта 2010 г., обраща-

1 Обоснование проекта об изменении уголовно-процессуального закона и некоторых других законов, издание №15042011b, www.ms.gov., с. 5-7.

2 Экспертизы вместе с отчетами о дискуссии опубликованы (w:) Biuletynach Komisji Kodyfikacyjnej Prawa Karnego [Бюллетенях кодификационной комиссии уголовного права] 2010, № 1, 2 и 3.

3 См. напр. C.Kulesza, Opinia dla Konferencji „Model postępowania przygotowawczego i sądowego”, Biuletyn Komisji Kodyfikacyjnej Prawa Karnego 2010, № 1, с. 76 и сл. На конференции выступили также с докладами: J. Skorupka, Model postępowania przygotowawczego i sądowego, Biuletyn Komisji Kodyfikacyjnej Prawa 
лось внимание на отзывы в польской доктрине уголовного процесса, критикующие, главным образом, её изменения, введенные вследствие новеллизации от 10 января 2003 г. (Dz. U.(Вестник Законов) № 155 ст. 111) и от 29 марта 2007 г. (Dz. U.(Вестник Законов) № 64 ст. 432). Предметом критики является, прежде всего, ослабление первой из реформ прокурорского надзора за производством, посредством отмены обязанности Полиции уведомлять прокурора о возбужденных расследованиях и создания возможности Полиции самостоятельно возбуждать следствия. ${ }^{4}$ В свою очередь, к основным недостаткам реформы от 2007 г. в доктрине уголовного процесса зачисляется введение жалоб на некоторые постановления прокурора, направленные к его непосредственному начальнику (вместо к вышестоящему) и увеличение объема подготовительного производства, имеющего своей целью „всестороннее объяснение обстоятельств дела” вместо введенного новеллизацией от 2003 г. „объяснения обстоятельств дела в необходимом объеме".5 В конечном счете, вследствие очередной новеллизации (Dz. U. (Вестник Законов) № 206 ст. 1589 ) от 8 июня 2010 г. произошел возврат к ограниченному объему подготовительного производства. кроме этого, было подвергнуто критике чрезмерное ограничение принципа непосредственности на фоне изменений польского уголовного процесса, особенно в случае консенсуальных методов окончания производства. ${ }^{6}$

В заключениях были указаны также результаты изучения материалов, из которых следует, что как «полицейское», так и упрощенное подготовительное производство, вследствие реформы от 2003 r., не убереглись от их затягивания (напр. вследствие необдуманного продления срока дознания и принятия его к следствию), помимо же ускорения судебного производства, из-за консенсуальных форм, по-прежнему, оно продолжается слишком долго, между про-

Karnego 2010, № 1, c. 27-74, D. Świecki, Model postępowania przygotowawczego i sądowego, Biuletyn Komisji Kodyfikacyjnej Prawa Karnego 2010, №1, c. 122-139 и A.Siemaszko, Sprawność postępowań karnych w świetle danych statystycznych, Biuletyn Komisji Kodyfikacyjnej Prawa Karnego 2010, №1, с. 140-167, см, также отзывы доктрины, относящиеся к проекту изменений УПК и других законов от 2011 г. напр. J. Tylman, Model procesu karnego a nadzór nad postępowaniem przygotowawczym. (в:) Państwo prawa i prawo karne. Księga jubileuszowa Profesora Andrzeja Zolla, Wolters Kluwer Polska, Warszawa 2012, t.II, c. 1803-1810 и указанная там литература.

4 Защитником самостоятельности Полиции в этой области является автор реформы от 10.01.2003 г. S.Waltoś, Kilka słów o polskim modelu postępowania przygotowawczego, B: Rzetelny proces karny. Księga jubileuszowa Profesor Zofii Świdy, (red. J. Skorupka), Wolters Kluwer business, Warszawa 2009, c. 293-294.

5 См. напр. J. Grajewski, Niektóre problemy nadzoru nad postępowaniem przygotowawczym i zakresu wpływu sądu na przebieg procesu karnego, (w:) Skargowy model procesu karnego. Księga ofiarowana Profesorowi Stanisławowi Stachowiakowi (red. A.Gereckiej- Żołyńskiej, P. Góreckiego, H.Paluszkiewicz, P. Wilińskiego), Warszawa 2008, c. 89-96; J. Tylman, Zmiany w modelu postępowania przygotowawczego, (w:) Skargowy model.., к.в., c. 387-398).

6 См. J. Tylman, Zasada bezpośredniości na tle zmian w polskim prawie karnym procesowym, (w:) Rzetelny proces karny. Księga jubileuszowa Profesor Zofii Świdy, (red. J. Skorupka), Wolters Kluwer business, Warszawa 2009, c. $125-144$. 
чим из-за чрезмерного обременения судов всесторонним исследованием доказательств, осуществляемым по долгу службы. ${ }^{7}$

Следует также обратить внимание на основную критику подготовительной функции вступительной стадии процесса, заключающуюся в констатации, что хотя существует возможность полного выявления, воспроизведения на судебном заседании и принятия за основу вынесения судебных решений любых протоколов доказательственной деятельности, составленных в подготовительном производстве, то польская модель подготовительного производства относительно этого вопроса не порвала с традициями бывшей советской модели. ${ }^{8}$

Критические замечания по отношению к существующему УПК высказали также эксперты на конференции от 6 июля 2010 г., посвященной применению мер пресечения. Они указали, между прочим, на необходимость усиления требований относительно применения самой суровой меры, то есть, временного ареста, соответствующего обоснования постановлений о временном аресте, более точного определения основы применения всех мер пресечения и принципов подачи жалоб на эти меры, а также укрепления, в этой области, права обвиняемого на защиту. ${ }^{9}$

Что касается конференции от 28 сентября 2010 г., посвященной модели обжалования судебных решений и приговоров и чрезвычайного обжалования решений и постановлений, то в связи с тем, что заключения экспертов представляли очень широкий спектр предложений, невозможным был здесь их анализ, поэтому, по данному вопросу, отсылаем к первоисточнику. ${ }^{10}$

Результаты этих конференций послужили предлогом для продолжающихся несколько месяцев дискуссий в кругу кодификационной комиссии, которые принесли плоды в виде разработки подготовительного проекта новеллизации Уголовно-процессуального кодекса и некоторых других законов, опубликован-

7 См. J. Błachut, S.Majcher, Szybkość postępowania przygotowawczego w świetle badań aktowych, (w:) Zagubiona szybkość procesu karnego. Światło w tunelu (red. S. Waltoś, J. Czapska), Kraków 2007, c. 67-149 а также D.Szumiło-Kulczycka, W. Dadak, Szybkość postępowania sądowego w świetle badań aktowych, в: Zagubiona., op. cit., c. 149-204.

8 C.Kulesza, Opinia..., op. cit., c. 77 и указанная там литература.

9 См. мнения: P.Kardasa, Środki zapobiegawcze w polskim procesie karnym - analiza aktualnego stanu prawnego w kontekście praktyki stosowania prawa oraz propozycje nowych rozwiązań ustawowych, Biuletyn Komisji Kodyfikacyjnej Prawa Karnego 2010, nr 1, c. 205-289; R.A. Stefańskiego, Środki zapobiegawcze w polskim procesie karnym de lege lata i de lege ferenda, Biuletyn Komisji Kodyfikacyjnej Prawa Karnego 2010, № 1, c. 309-327 и замечания B. Michalskiego - опубликованные в Biuletynie Komisji Kodyfikacyjnej Prawa Karnego [Бюллетене Кодификационной комиссии уголовного права] 2010, № 2., с. 290-308

10 См. A. Herzog, Model postępowania odwoławczego oraz postępowania w sprawie nadzwyczajnych środków zaskarżenia, Biuletyn Komisji Kodyfikacyjnej Prawa Karnego 2010, № 1, c. 193-209; K. Marszał, Stanowisko w sprawie wstępnych założeń reformy postępowania odwoławczego oraz postępowania w trybie nadzwyczajnych środków odwoławczych, Biuletyn Komisji Kodyfikacyjnej Prawa Karnego 2010, № 2, c. 21-31; M. Klejnowska, Model postępowania odwoławczego i nadzwyczajnoskargowego w sprawach karnych, Biuletyn Komisji Kodyfikacyjnej Prawa Karnego 2010, № 2, c. 32-61; J. Izydorczyk, Analiza rozwiązań dotyczących postępowania odwoławczego oraz postępowania w trybie nadzwyczajnych środków zaskarżenia- opublikowane w Biuletynie Komisji Kodyfikacyjnej Prawa Karnego 2010, № 2., c. 210-236 
ного в феврале 2011 г. Это дало начало всесторонним консультациям в профессиональной среде, в рамках которых было представлено несколько сотен позиций и мнений, которые в следующем подверглись анализу, проведенному кодификационной комиссией.

Подготовлен в 2011 г. кодификационной комиссией уголовного права проект изменений Уголовно-процессуального кодекса должен теоретически являться комплексной новеллизацией, имеющей своей целью моделирование польского уголовного процесса в целом.

Согласно основным положениям, авторов проекта главные цели реформы, это ${ }^{11}$ :

- „моделирование юрисдикционного производства в направлении большей состязательности, которая создает лучшие условия для установления материальной истины и лучше способствует соблюдению прав участников судопроизводства,

- моделирование - в объеме, необходимом для построения модели состязательного судебного разбирательства - подготовительного производства, главным образом, в области целей, к достижению которых стремится данное производство,

- улучшение и ускорение производства, благодаря созданию правовых рамок более широкого применения консенсуальных методов окончания уголовного судопроизводства и использования, в более широком масштабе, идеи исправительной/правовой справедливости, благодаря также новому подходу к институту медиации,

- устранение „мишуры” судопроизводства, благодаря новому определению способа вынесения судебных решений, основанного на отказе от ряда действий, которые не служат ни установлению истины в процессе, ни соблюдению гарантий участников судопроизводства, ни реализации принципа справедливого наказания,

- формирование заново основ применения предупредительных мер методом, предотвращающим их чрезмерное использование в процессуальной практике, лучше гарантирующим достижение их основной цели, какой является обеспечение правильного хода производства, а также лучше защищающим процессуальные гарантии обвиняемого и позволяющим на предъявление притязаний и поиск их удовлетворения посредством возмещения ущерба и вреда, вызванных применением этих мер в ходе производства, 
- ограничение затягивания производства, благодаря новому формированию модели апелляционного производства, ограничивающему его кассационность, способствующую затягиванию уголовного судопроизводства".

Предлагаемая комиссией модель судопроизводства базируется на предположении, что действия по исследованию доказательств в ходе подготовительного производства проводятся в принципе для обвинителя, а не, как в настоящее время, для суда. Лишь в исключительной ситуации, когда представление доказательства перед судом не будет возможным - собранные и зафиксированные в подготовительном производстве доказательства „будут использоваться судом как основа установления фактов по делу". Дело касалось бы, по мнению комиссии, прежде всего доказательств по своей натуре „неповторимых”, или следов ( в том числе, мнемотехнических), подвергающихся забвению с течением времени. Поэтому, предполагая полную состязательность судопроизводства, авторы проекта не видят потребности в основных изменениях модели подготовительного производства, ограничиваясь к изменению его целей, определенных в ст. $297 \S 1$ п. 5 УПК. Предлагаемый текст этого положения „сбор, обеспечение и (...) фиксация доказательств, с изелью представления их в суде” по мнению комиссии, должен толковаться, как „директива по сбору и фиксации доказательств в объеме, который является необходимым для поддержки обвинительной жалобы и возможности реализации роли, какую обвинителю придется исполнять после подачи обвинительного акта”. ${ }^{12}$

Как вытекает из заглавия настоящей разработки проектируемая реформа процедуры уголовного судопроизводства влияет, существенным образом, на вид действующих процессуальных принципов.

Главным способом регулирования, имеющего своей целью обеспечить принцип состязательности судопроизводства, должна быть новая редакция ст.167 УПК, освобождающая Суд от обязанности доказательственной инициативы на судебном заседании и поиска, по долгу службы, объективной истины, а также возлагающая на процессуальные стороны onus probandi. В ходе работ комиссия, однако, решилась - замечая потенциальные угрозы, вытекающие из передачи судьбы процесса, с целью установления объективной истины, в руки сторон - на некоторые исключения из принципа полной состязательности. Окончательная редакция ст. 167 УПК звучит:

„Ст. $167 \S 1$. В производстве перед судом, возбужденном по инициативе стороны, доказательства представляются сторонами после допущения их председателем или судом. В случае неявки стороны, по заявлению кото- 
рой была разрешена допустимость доказательства, а также в исключительных, особо обоснованных случаях, доказательство представляет суд в пределах доказательственного тезиса. В исключительных, особо обоснованных случаях суд может допустить и представить доказательство по долгу службы.

$\S 2$. В другом производстве перед судом или в подготовительном производстве доказательства представляет орган, ведущий производство. Это не исключает права стороны на подачу ею заявления о допущении доказательства".

В обосновании регуляции $\S 1$ ст.167 УПК подчеркивалось, что с одной стороны, она освобождает Суд от доказательственной активности в случае пассивности, по отношению к этому вопросу, обвинителя, с другой же стороны этот Суд будет, „в меньшей, чем до сих пор степени, исполнять роль гаранта по отношению к обвиняемому, на которого - как сторону в процессе - будет возложено в большей, чем до сих пор степени бремя доказывания в материальном значении". ${ }^{13}$

Таким образом, доказательство на судебном разбирательстве будет представлять та сторона, которая заявляла о нем. Так как проект новеллизации, в принципе, не предусматривает обязательного участия обвиняемого в судебном заседании, поэтому второе предложение $\S 1$ ст.167 УПК устанавливает, что в случае неявки стороны, по заявлению которой доказательство было допущено, а также в исключительных, особо обоснованных случаях суд представляет доказательство в пределах доказательственного тезиса. Зато наиболее радикальным исключением из принципа состязательности должна быть возможность допустимости и представления судом доказательства по долгу службы, однако, опять „, в исключительных, особо обоснованных случаях” (§ 1 ст.167 предл.3).

Укреплению принципа состязательности на судебном заседании должно способствовать также предлагаемое изменение ст. 370 УПК, определяющее порядок производства допроса. Проект устанавливает, чтобы в случае производства допроса стороной, она всегда, в первую очередь, задавала вопросы допрашиваемому лицу, а члены суда имели бы на это право только исключительно и всегда бы это делали в последнюю очередь (ст. $370 \S 1$ и 2 проекта УПК).

Проектируемое изменение ст.167 УПК коренным образом повлияет на цели уголовного процесса. Проект сохраняет существующую форму принципа материальной истины, определенной в ст. 2 § УПК, устанавливающей, что основу всех решений должны составлять настоящие фактически обстоятельства. Однако существующую до сих пор цель процесса, определенную 
в ст.2 1 п.1, то есть, сформирование процесса таким образом, чтобы „исполнитель преступления был установлен и привлечен к уголовной ответственности, а невиновное лицо не несло этой ответственности" заменено во второй части предложения формулировкой, ,, а лиць, вина которого не доказана, не несло этой ответственности”. По мнению комиссии, такая формулировка отчетливо подчеркивает, что вменение вины в процессуальном смысле не будет возможным, если перед судом не будет представлено доказательство вины. ${ }^{14}$

В проекте была придана также новая форма принципу in dubio pro reo(cт.5 $\S 2$ УПК), тесно связанному с принципом презумпции невиновности, так как существующее до сих пор правило о толковании неустранимых сомнений в виновности лица в пользу обвиняемого было заменено правилом толкования в пользу обвиняемого сомнений, которые в производстве не были устраненьл. как подчеркивается в обосновании проекта это регулирование, по-прежнему, не определяет, на кого возложена обязанность объяснения этих сомнений, однако не возложена она на суд, так как он - по существу - не обязан представлять доказательства по долгу службы. Отказываясь от существующей до сих пор оговорки, что это должны быть „неустранимые” сомнения, предполагается, что благодаря этому на обвинителя будет возложена обязанность устранить сомнения (а в материальном смысле также на защиту). ${ }^{15}$

Последствием освобождения - по общему правилу - суда от обязанности искать материальную истину по долгу службы и возложить ее, прежде всего на обвинителя является также признание ему права на эффективный отзыв обвинительного заключения, то есть, принятие неограниченного обвинительного принципа (ст.14 УПК). как подчеркивается в обосновании проекта такой отзыв обвинительного заключения будет чем-то совсем другим, чем предусмотренный в настоящее время в ст.14 § 2 УПК отказ от обвинения, так как это вызовет необходимость прекращения судопроизводства на основе ст. $17 \S 1$ п. 9 УПК, из-за отсутствия обвинения управомоченного обвинителя. Однако в ходе судебного процесса отзыв обвинительного заключения будет допускаться исключительно с согласия обвиняемого (проект. ст. $14 \S 2$ второе предложение УПК), ибо в противном случае обвинитель мог бы односторонним процессуальным действием довести до прекращения производства в ситуации, в которой существуют предпосылки для оправдания обвиняемого. ${ }^{16} \mathrm{C}$ целью защиты интересов субсидиарного обвинителя предусмотрено изменение в проект. ст. $54 \S 2$ УПК, согласно которой отзыв обвинительного заключения публичным обвинителем не лишает правомочий субсидиарного обвинителя. В такой ситуации пострадавший, который раньше не пользовался правомочиями субсиди-

Обоснование, с. 16.

Там же, с. 17.

Обоснование, ор. cit. 
арного обвинителя, вправе заявить, в течение 14 дней от извещения его об отзыве публичным обвинителем обвинительного акта, что вступает в процесс в качестве субсидиарного обвинителя. ${ }^{17}$

На предлагаемые изменения следует смотреть с перспективы принципа обеспечения обвиняемому права на защиту. На основе ст. 42 абз. 2 конституции и регулирования по отношению к ст. 6 УПК считается, что право на защиту в польском уголовном процессе включает как материальный аспект (как совокупность гарантий защиты в процессе, полагающихся обвиняемому), так и формальный, то есть, возможность пользоваться обвиняемым помощью защитника.

В системе уголовного процесса, где суд осуществляет также функцию защиты, этот факт вызывает некое уравновешение неравенства между защитой (материальной и формальной) и стороной обвинения, представляемой публичным обвинителем и подчиненным ему органом уголовного преследования. Если , суд, по воле законодателя, будет освобожден от этой функции или, как гласит кодификационная комиссия, перестанет исполнять „патерналистскую” роль по отношению к обвиняемому, реальная обязанность защиты будет возложена на обвиняемого и его защитника. ${ }^{18}$

В существующем правовом положении можно констатировать, что „формальный” характер защиты, осуществляемой адвокатом, каким-то образом оправдан с одной стороны обязанностью поиска судом объективной истины по долгу службы, с другой же стороны предусмотренной законом связью суда и прокуратуры (похоже, как и органов преследования) на основе принципа объективизма (ст.4 УПК). Поэтому действия защитника не обязательно должны иметь решающее влияние на результат процесса, особо в ситуации, когда он не может реальным образом воздействовать на ход и результаты подготовительного производства. ${ }^{19}$ кодификационная комиссия решила отказаться от осуществления модельных изменений этой вступительной стадии процесса, принимая предположение, что судьбы производства будут решаться только на главном судебном разбирательстве. Вышеуказанное предположение авторов проекта, при не измененной позиции защиты, кажется сомнительным, по крайней мере, хотя бы из-за нижеприведенных обстоятельств.

Прежде всего, проект изменений УПК оставляет практически в неизменном виде инквизиционный характер подготовительного производства, сохра-

17 Там же, с. 20.

18 См. также P. Wiliński: Materialny ciężar dowodu winy oskarżonego - przyczynek do rozważań, (w:) Państwo prawa i prawo karne. Księga Jubileuszowa Profesora Andrzeja Zolla, Wolters Kluwer Polska, Warszawa 2012, c. $1841-1856$.

19 См. шире C.Kulesza, Od obrony formalnej do obrony realnej ? Nowa rola obrońcy w projekcie reformy procedury karnej (в:) Księga Jubileuszowa Prof. J. Skupińskiego (принятая к публикации). 
няя прежние ограничения права на защиту, в том числе, между прочим, в области ознакомления с материалами подготовительного производства в условиях, определенных в ст. $156 \S 5$ УПК, отказа в удовлетворении процессуальных заявлений на основе ст. $170 \S 1$ и ст. $170 \S 1 \mathrm{a}$, а также участия в процессуальных действиях, о которых идет речь в ст. 315-317 УПК. В результате возможным является основание приговора на доказательственном материале, зафиксированном в подготовительном производстве, без соблюдения принципа состязательности (без участия и контроля защитника). Несмотря на вышеуказанное ограничение задач подготовительного производства (изменение ст. $297 \S$ 1 п.5) следует отметить, что проектируемые исключения из принципа непосредственности позволяют на оглашение, по заявлению или в ситуации определенной в ст. $167 \S 1$ предл. 3 и ст. $167 \S 2$, а также по долгу службы, протоколов объяснений обвиняемого (ст.389 УПК), показаний свидетеля (ст. 391 УПК) и других документов (ст.393 УПК), а также выявление их без оглашения (ст.394 УПК), и все это даже в более широком объеме, чем в настоящее время. Ибо следует заметить, что учитывая факт, что обвиняемый не будет обязан (теоретически) участвовать в судебном разбирательстве, правилом будет оглашение его объяснений, новая же редакция ст.393 § 3 УПК разрешит оглашать любые частные документы, полученные вне уголовного судопроизводства. Хотя отмена запрета использования в уголовном судопроизводстве частных документов должна служить принципу „равенства оружия” (как определяет это проект „выравниванию шансов” $)^{20}$, однако авторы проекта расширяют запрет по ст. 174 УПК замены протоколов объяснений обвиняемого и свидетелей не только содержанием писем, аннотаций или служебных записок (как это происходит в настоящее время), но также других документов.

Выравниванию шансов защиты и обвинения должно служить также введение проектом допустимости так называемых частных заключений экспертов. У обороны также будет возможность подать заявление о допущении доказательства, основанного на заключении эксперта (которое составил для защиты) и допроса эксперта в судебном заседании, если суд согласится допустить это доказательство.

Стоит также задуматься, будет ли в новом УПК у обвиняемого право на пассивную защиту, что сейчас является одним из последствий действия принципа презумпции невиновности. Хотя авторы проекта не решились принять предлагаемую некоторыми экспертами концепцию пресекательного срока на предъявление доказательств ${ }^{21}$, однако концепция состязательного процесса,

20 Обоснование, с. 13.

21 См. M. Jeż-Ludwichowska, Krytycznie o koncepcji prekluzji dowodowej, (w:) ludicium et Scientia. Księga jubileuszowa Profesora Romualda Kmiecika (red. A. Przyborowska- Klimczak i A. Taracha), Wolters Kluwer, Warszawa 2011, с. 539-552 и указанная там литература. 
возлагая на сторону защиты материальное бремя доказательства, потребует от неё некой процессуальной активности. Итак, важной задачей защитника будет участие в таких процессуальных действиях, как:

1) участие в ознакомлении с материалами на последней стадии подготовительного производства, в течение которого проектируется проведение селекции доказательственного материала, который прокурор намерен предъявить в суде (ст.321 § 3 и 5 проекта)

2) выражение согласия на вынесение приговора без судебного разбирательства в порядке ст. 335 УПК, где помощь защитника является не только существенной, но также в значительной степени затруднительной, прежде всего в случае отказа в предоставлении ему материалов дела на основании неизмененного проектом регулирования по отноше-

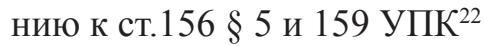

Уже в судебном производстве (также до начала разбирательства) очень важной является помощь защитника при:

1) подаче заявлений о допущении доказательств и заявлений об обязанности прокурора дополнить материалы подготовительного производства, приложенные к обвинительному акту, определенными документами, содержащимися в материалах этого производства (ст.338 $§ 1$ проекта)

2) подаче, еще до извещения обвиняемого о дате и времени судебного заседания, заявления о вынесении обвинительного приговора и назначении ему определенного наказания или уголовной меры наказания без проведения производства по исследованию доказательств (ст.338 а проекта). Согласно проекту может он относиться ко всем преступлениям, в случае же менее тяжкого преступления создает возможность направления дела на заседание и применение чрезвычайного смягчения наказания (ст. 343 а проекта)

В ходе главного судебного разбирательства, несомненно, важную роль будет играть подача заявлений о допущении доказательств (например о допущении частного заключения эксперта) а также допрос лиц, в качестве источника доказательств, согласно проектируемым изменениям ст.167 и 370 УПК.

В кассационном производстве следует обратить внимание на один рефлекс пресекательного [преклюзивного] срока на представление доказательств. Итак, проект вводит..."для стороны, которая проявляла на этапе производства 
в суде первой инстанции пассивность и отсутствие инициативы в предъявлении доказательств (относительно заявления о представлении доказательств или активности при предъявлении допущенного судом доказательства) - барьер в обвинении суда как в том, что он не согласился на допустимость или не предъявил определенных доказательств по долгу службы, так и в том, что воспользовался, в исключительном порядке, одной из этих прерогатив, несмотря на пассивность стороны. Соответствующее решение предложено в ст. $427 \S 4$ УПК, а по отношению к производству, оконченному вынесением приговора, запрет в выдвижении таких обвинений в апелляционном порядке конкретно выражен в проект. ст. $447 \S 5$ УПК”. 23

Эти ограничения не будут относиться к доказательствам, представление которых будет обязательным (ст. 447 § 6 УПК), например допущение судом заключения экспертов-психиатров в качестве судебного доказательства.

Замечая важную роль защитника в процессе, проект как принцип принимает возможность воспользоваться подозреваемым правом бедности на этапе подготовительного производства (ст. 78 § 1 УПК), и общим правом назначить защитника по долгу службы на этапе судебного производства (ст. 80а УПК). Итак, на этапе подготовительного производства, по-прежнему, назначение судом защитника по долгу службы будет требовать от подсудимого доказания отсутствия возможности покрыть необходимые для этого расходы. В судебном производстве назначение судом защитника по долгу службы (в других случаях, чем ст. $79 \S 1$ и 2, а также ст. 80 УПК) будет происходить по заявлению обвиняемого с учетом его имущественного положения. ${ }^{24}$ Однако следует указать на существенную модификацию предлагаемой кодификационной комиссией возможности воспользоваться обвиняемым назначением защитника по долгу службы, какую ввело Министерство юстиции в версии проекта от 4 октября 2012 г., направленную на заседание Совета Министров 9 октября 2012 г. Важным изменением, с точки зрения всеобщности использования помощи защитника по уголовным делам, следует считать предоставление полномочий по выполнению этой функции, кроме адвокатов, также юрисконсультам (см. изменение ст. 80 и сл.). Однако ст.80 была модифицирована посредством добавления § 1 а в следующей редакции: „1 а. Обвиняемому разъясняется также содержание положений ст. 80а, ст. 291 §, ст. 338а, ст. 341 § 1, 349 §, ст. 374, 376, 377 и 422, а также предупреждается его об обязанности оплаты сбора за подачу заявления о назначении защитника, вытекающей из ст. 14а закона от 23 июня 1973 г. об уплате сборов по уголовным делам (Dz. U. [Вестник зако-

23 См. напр. C. Kulesza, Porozumienia procesowe z perspektywy obrońcy, (w:) Ocena funkcjonowania porozumień procesowych w praktyce wymiaru sprawiedliwości (red. C. Kulesza), Wolters Kluwer business, Warszawa 2009, c. 65-81 и указанные там результаты исследований. 
нов] от 1983 г. № 49, ст. 223, с дальнейшими изменениями), а также о том, что в зависимости от результата процесса на обвиняемого могут быть возложены судебные издержки по назначению защитника по долгу службы “.

Подводя итоги всего вышесказанного, следует отметить, что предлагаемая реформа уголовного судопроизводства может вызывать сомнения с точки зрения некоторых процессуальных принципов, в том числе, принципа материальной истины. ${ }^{25}$ Перенос бремени доказывания на процессуальные стороны (в том числе, на защиту), вместе с широким масштабом консенсуальных форм окончания производства, может углублять сомнения, вытекающие из их существующего до сих пор функционирования. ${ }^{26}$ Новеллизация, несомненно, возлагает новые обязанности на защиту, обременяя её, реальным образом, общей ответственностью за результат процесса. Поэтому можно опасаться, не перечеркнут ли финансовые обстоятельства, связанные с широким участием защитников в уголовном судопроизводстве (в том числе, также юрисконсультов), идеи широкого доступа обвиняемых к правовой защите. В противном же случае прежнюю актуальность сохранит правило Анатоля Франса, который уже много лет тому назад заметил, что: "Закон, имея в виду свое величественное равенство, запрещает как бедным, так и богатым спать на улице, нищенствовать и воровать хлеб”.

25 См. напр. J. Skorupka, Zasada prawdy materialnej w projekcie noweli kodeksu postępowania karnego opracowanym przez Komisję Kodyfikacyjną Prawa Karnego, (w:) Państwo prawa i prawo karne, op. cit., c. 17451756.

26 R. Kmiecik, O zasadzie prawdy materialnej, konsensualizmie i gwarancjach procesowych osoby niewinnej, (w:) Zasada prawdy materialnej Materiały z konferencji, Krasiczyn 15-16 października 2006 (red. Z. Sobolewski, G. Artymiak), Zakamycze 2006 s. 148-149. Zob. także: H. Paluszkiewicz, S. Stachowiak, Rozwiązania konsensualne wprowadzone do polskiego procesu karnego a wykrycie prawdy, (w:) Zasada prawdy materialnej. op. cit. s. 91-110; Z. Świda, W. Jasiński, M. Kuźma, Dyrektywa rozstrzygania sprawy „w rozsądnym terminie” a realizacja zasady prawdy materialnej w polskim procesie karnym, (w: ) Zasada prawdy materialnej, j.w., s. 2023; 


\section{THE PROPOSED AMENDMENT TO THE POLISH CRIMINAL PROCEDURE FROM THE PERSPECTIVE OF SOME OF THE PROCEDURAL PRINCIPLES}

The article aims to present the analysis of the future reform of criminal procedure from the perspective of certain procedural principles. The foundation of the proposed amendment is the principle of an adversarial hearing and the release of the Court from the obligation to carry out evidence ex officio. The reform provides also for the extension of the scope of procedural agreements leading to the accelerated completion of criminal proceedings.

Such proposals may raise concerns from the point of view of the principle of objective truth and the principle of equality of arms. Pursuant to art. 42 (2) of the Constitution and to art. 6 of the CCP, it is believed that the right to defence in the Polish criminal process covers both the substantive aspect (as the sum of guarantees given to the defendant with regards to his defence in a process) and the formal aspect (the defendant's right to receive assistance of a defence counsel). Even though the quality of a defence counsel's work should be considered as one of the guarantees of due process, it must be stated that, in the context of the Polish criminal process system in the 21 st century, there are constraints on the effectiveness of the defense that are independent of the defense counsel's efforts.

Key words:

Reform, criminal procedure, adversarial hearing, objective truth, right to defence. 